\title{
REFERENCES.
}

1. Witthaus and Becker. Text-book of Medical Jurisprudence, vol. iv. p. 662 .

2. Norman Kerr. Twentieth Century Practice, vol. iii. p. 71 .

3. Quoted in American Year Book of Medicine and Surgery, 1901.

4. Witthaus, loc. cit.

5. Quoted by Witthaus, loc. cit.

6. Cortright, C. B. A Case of Atropine Poisoning. New York Medical Journal, Sept. 5, 1903.

7. Wood, H. C. Text-book of Therapeuties, 11 th ed., p. 175.

8. Quoted hy Wood, loc. eit.

9. Bond. British Medical Journal, 1881, p. 639. Quoted by Witthaus.

10. Therapeutic Monthly, May, 1901. Quoted by American Year Book of Medicine and Surgery, 1902.

11. Philadelphia Medical Journal, January, 1901.

12. Small. Twentieth Century Practice, vol, iii. p. 513.

\section{THREE CASES OF PERNICIOUS ANAMIA, WITH A DESCRIPTION OF THE PATHOLOGICAL CHANGES FOUND IN THE SPINAL CORD.}

\author{
By Robert Reuling, M.D., \\ OF BALTIMORE, MD.
}

CASE I.-W. H., male, aged forty-six years; white, born in the United States; widower. Was seen by me in consultation during December, 1901. His occupation has been variable. For several years he was clerk in the Baltimore \& Ohio Railroad office. For six years he travelled as salesman for a commercial house, and at thirty-five years he settled in South Carolina, where he started a small general store in one of the small towns in the northeastern part of the State. His family history is negative. No history of tuberculosis, anæmia, or neuroses. He has always lived fairly well, but in his occupation as salesman his food was frequently not of the best, and he had frequent attacks of gastric discomforts. His stomach became so deranged that his general health was much affected, so that he gave up his position as salesman and went into business for himself. As a child when six years old he had scarlet fever. Pneumonia when seventeen years old. No sequelæ. From his nineteenth to his twenty-third year he was very nervous, apparently suffering from sexual neurasthenia. Gonorrhœe at twenty-two years, without complications. No history of syphilis or its secondary manifestations.

The patient dates his present illness from an attack of fever and marked malaise, associated with severe muscular pains, which was pronounced influenza by the attending physician. This was in November, 1899 . He remembers several people that were similarly affected in the town; he was living in South Carolina at the time. He remained in bed for almost three weeks, and from his description the myalgia must have been unusually severe; the pains were espe- 
cially marked along the spine and in the muscles of the legs. The fever was high and lasted about six days. There was gastric disturbance, marked nausea, but no vomiting. Bowels constipated. On leaving his bed he felt extremely weak, very depressed, and had lost much flesh. After two months he began to feel somewhat better, but he was still not the same man, and anorexia, with mental depression, was still present. About six months after this illness he was taken suddenly ill with severe pains in the abdomen coming on during the night, almost constant vomiting for forty-eight hours, and marked diarrhœea, with tenesmus. The prostration must have been pronounced. This disturbance was apparently due to eating ice-cream and drinking considerable beer later. He now began to have frequent attacks of gastric disturbance, and he says "his stomach has not been right since." As a rule, anorexia, rarely vomiting, but considerable gastralgia have been persistent symptoms during the last year or more. The extreme pallor was first noted one year ago and has been gradually increasing. The patient was treated six months ago in Greensborough, North Carolina, and thinks he was given quinine, arsenic, and iron. He thinks he has had some little fever at intervals. He improved for a time, but six weeks ago he decided to visit relatives in Baltimore, as he realized his disease was taking a serious course. The journey north tired him a great deal, and he almost fainted in the station here, and in Washington he was obliged to take whiskey at short intervals. His friends here were shocked at his appearance. He was treated by a physician, who pronounced the case cancer of the stomach, and advised operation. As a medical student was living in the house in whose ability the people had confidence, they asked his opinion about the case, and, as he differed from the former diagnosis, I saw the case as a third party.

Notes at Bedside. A man of large frame, looks older than forty-six years. Extremely anæmic tongue, lips and finger-nails show extreme pallor. He is still fairly nourished, but signs of loss of flesh apparent. The skin in general has a dirty, very light lemon color; this is more marked over lower abdomen and the face. Hair is gray and very dry. Breath bad. Several decayed teeth, especially the left first molar. No pus apparent about the teeth. Tongue coated slightly, thickened, but not tender. No subcutaneous hemorrhages. Lungs clear on auscultation and percussion. Heart impulse just in nipple line; soft blowing systolic murmur over body of heart, not transmitted to right or left. Liver not enlarged, not tender. Abdomen in general looks natural. Stomach area about normal on percussion. Deep pressure in epigastrium gives rise to some pain, and the patient is immediately nauseated. Slight cedema over dorsum of the feet and over ankles. Both patellar reflexes are abolished; the plantar reflexes are still present. No apparent atrophy of any group of muscles. No sensory disturbance elicited; feels heat and cold every- 
where. When asked to walk there is no difficulty apparent. There is, however, considerable Romberg symptom present. When the patient attempts with eyes closed to touch the knees with the heel of the opposite foot he comes rather wide from the mark, and there is a slight ataxic swaying of the extremity. It is difficult to say if this is a true ataxia, as the extreme muscular weakness might account for it. No bladder or rectal disturbance. Vision good.

Ophthalmoscopic examination shows two punctiform hemorrhages in the right eye in the lower quadrant of the fundus and a small hemorrhage just at the edge of the disk in the left eye. No nystagmus. Pupils react to light and accommodation.

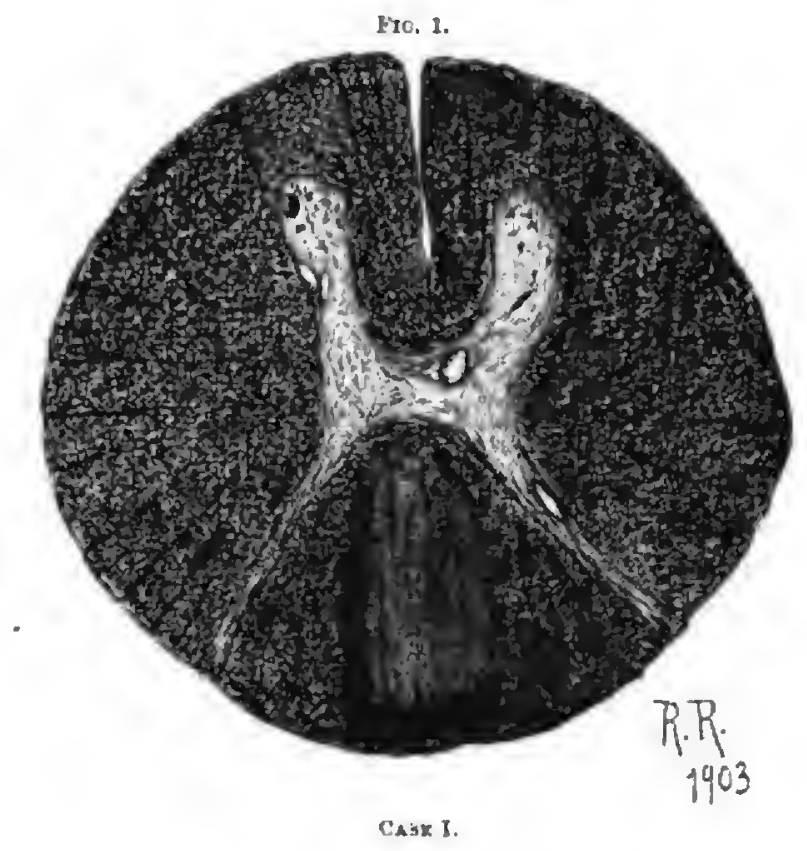

Blood Examination. 1,800,000 erythrocytes, 7000 leukocytes, and 22 per cent. hæmoglobin. Specimens were stained after drving on copper plate and also after fixing in absolute alcohol and ether. Specimens show a marked poikilocytosis; almost every corpuscle is distorted. Many microcytes and a few macrocytes and about forty nucleated red blood cells were found in a blood smear. The first specimen showed no megaloblasts; the second, which was examined with the sliding stage, showed six. They were typical. Urine contains a trace of albumin; specific gravity, 1016. No casts; no diazo.

The patient was seen four or five times, but I made only two personal blood examinations, and, as my student friend had little opportunity to carry these out, my report is rather incomplete. 
When last seen the blood count had improved slightly, 2,000,000, but there are several megalocytes now seen in the stained specimen, February 11, 1902. The patient died on March 2, 1902, from bronchopneumonia.

A complete autopsy was not granted, and I was only allowed to remove the cord, and this was not an easy matter in a private home.

Description of Cord. No macroscopic changes evident; meninges normal.

Description of Microscopic Changes Found in the Spinal Cord in Case I. Small pieces from every portion of the cord and medulla were placed in formalin and in a mixture of Müller's fluid and formalin. After hardening they were stained by the Weigert, WeigertPal, Van Gieson, and eosin and hæmatoxylin methods. In this case the Marchi stain was not employed. In every specimen examined, no matter what the staining method was, it was quite evident that a narrow strip of degeneration was present in both the column of Goll and that of Burdach, most marked in the former in most sections. The degeneration was most apparent in the lower cervical and upper dorsal regions. The drawings from this case were made from specimens stained by the Weigert-Pal staining method, and the blanched area in the posterior tracts of the cord represents the degenerated fibres. In the Van Gieson specimens it was clearly shown that these degenerated fibres had lost their myelin sheaths, and very few axis-cylinders could be made out in the degenerated areas. The remainder of the cord was absolutely normal. There. were no hemorrhages found; the bloodvessels were normal, as were also the meninges. In all sections examined the same degeneration was apparent as far down as the upper sacral cord.

CASE II.-This case is of special interest, I think, in that the spinal symptoms seemed to precede the onset of the anæmia. Mrs. $M$., seen in November, 1902, aged thirty-four years; mother of two children, and who has had two stillbirths; the last child was born when seven months old, in 1900. Family history negative, except that one maternal uncle died of phthisis. She has had scarlet fever and measles. Typhoid fever at twenty years. No sequelæ. Has been of a neurotic disposition, and for several weeks during her first pregnancy was quite hysterical. No history of syphilis or its secondary manifestations.

She dates her present trouble to her last pregnancy, which resulted in a miscarriage at the seventh month of gestation, in 1900. She had fever for three weeks after this, and was a very sick woman. No marked rigor, but chilly feelings. Some muscular pains, but these were not marked. No swelling of the joints. After spending seven weeks in bed she was allowed to sit up, but was too weak to walk, even about the room. She has always had a rather sallow complexion, but has generally weighed between 130 and 135 pounds. In the early part of 1901 the patient was still run down, but was able 
to attend to light household duties. About this time she noticed a peculiar feeling and sensation of cold in the right thigh; this was especially marked when fatigued. Later a very similar sensation was noticed in the left thigh, but more over the buttocks. At times she had a feeling as though hot water was being poured over her lower extremities. This was nothing that troubled her. In August, 1901, she was in a driving accident, which left her very nervous, and she was subject to crying spells and suffered with pain down the back, and she seemed to have slight difficulty in walking, especially in the dark. No lancinating pains, but she still felt the sensations described above. She began to suffer with her stomach, and had constant feelings of weight in the epigastrium, and the pressure

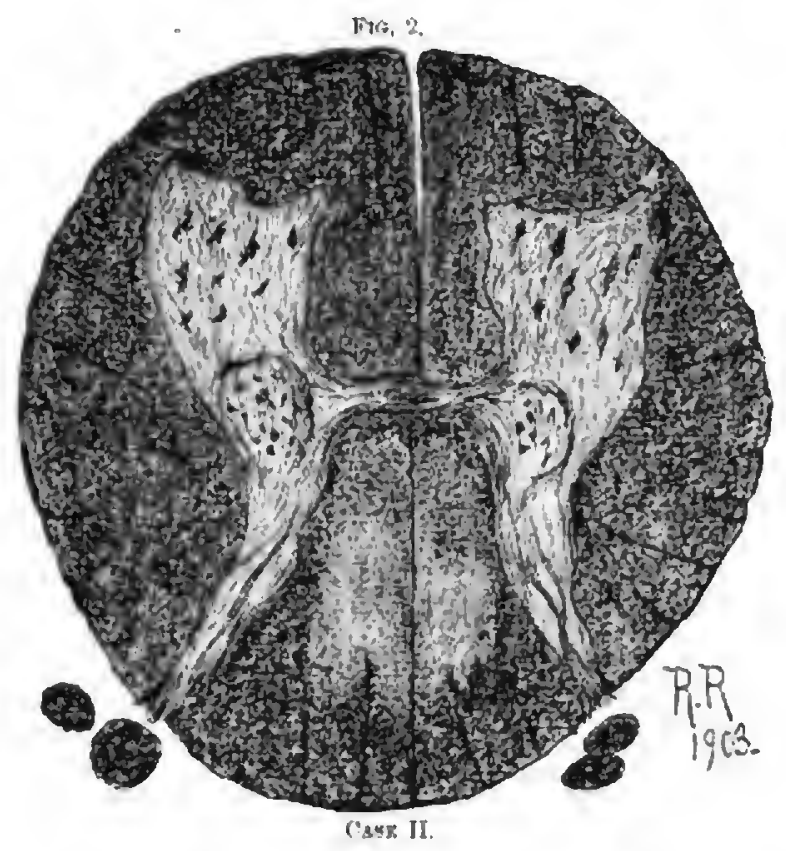

of clothing was very annoying. She did not vomit, but was frequently nauseated, especially in the morning. At this time she began to get pale. She took iron and quinine, probably arsenic, but her anæmia, except with periods of improvement, has steadily increased.

Notes at Bedside. A moderately well-nourished woman; subcutaneous fat well preserved. She is extremely pale, and the skin has a faint suggestion of a yellow tinge. Tongue coated and rather sensitive to pressure and feels hard and is somewhat thickened, espepecially the anterior two-thirds. Teeth in fairly good condition. No glandular enlargement. Hair very dry and without lustre; not gray. Lungs clear throughout, except a few moist râles at the left base. Heart: A very loud hæmic murmur over the base, which is 
transmitted to the vessels of the neck. Apex-beat about the nipple line. Liver slightly below the costal border, $3 \mathrm{~cm}$. Stomach is also displaced downward. The right kidney is readily palpable and slightly movable; in fact, a moderate degree of Glénard's enteroptosis exists. T'est meal shows trace of hydrochloric acid. No lactic acid. Motor function of stomach evidently sluggish and some hypersecretion present.

Blood Count. 2,000,000 erythrocytes, 9000 leukocytes, and 32 per cent. hæmoglobin. Stained specimen with Ehrlich's triple stain shows marked poikilocytosis. Microcytes numerous; also macrocytes in several fields; and in about every fourth or fifth field an atypical megaloblast is visible, with very dark nucleus. Beautiful karyokinetic figures are seen in some of the nucleated corpuscles, and several erythrocytes show the polychromatophilic degeneration.

Examination of Nervous System. Gait is rather stiff, but no typical ataxia when the eyes are open. She watches the floor very intently. With closed eyes there is evidently a slight ataxia. Wellmarked Romberg symptom. Both patellar reflexes absent. Plantar reflex present. No Babinsky reflex. No atrophy of any muscles. Apparently a slight dulling to the differentiation of heat and cold over the right thigh, but this is slight. Touch normal. No other sensory disturbance; patient says she is rarely free lately of the paræsthetic sensations in the lower extremities. No lancinating pains present. Has never noticed any bladder or rectal symptoms. Paticnt seen on one more occasion, and this was two weeks before her death, which occurred in January, 1903. Post-mortem limited to removal of cord and brain and inspection of abdominal viscera, which could not, however, be removed.

Cord. Macroscopic appearance normal.

Description of Microscopic Examination of Cord from Case II.The entire cord was removed and sections from all regions placed in formalin, Müller's fluid with formalin added, also a few sections stained by the Marchi method, besides Van Gieson and eosin and hæmatoxylin staining. In all sections from whatever regions of the cord, except the very lower dorsal, ninth to the twelfth segments, and the sacral portion, a well-marked degeneration, involving almost the entire posterior tract of fibres, including the columns of Goll and Burdach. In this, as in the former case, the change was most pronounced in the upper dorsal and lower cervical regions. With the Weigert-Pal method a slight blanching of both right and left lateral columns was evident, but it was only after using the Marchi stain that it became evident that a considerable number of nerve fibres had degenerated in these lateral areas, this degeneration being probably of recent date. The anterior portion of the cord was normal. No hemorrhage found. The bloodvessels, nerve cells, and meninges were apparently normal. Nissl's stain was not employed, so one can say nothing in regard to the nerve cells, except that they showed no marked shrinkage. 
In this case the reader will remember that there was evidence of spinal disease preceding the onset of anæmia for several months; in fact, the pronounced paræsthesias rather diminished toward the end of the disease. Several cases of this description are now found in the literature. It is most probable that more than one toxin exists in pernicious anæmia, one having a predilection for causing degenerative changes in the red blood cells, while the other seems to have a special affinity to the spinal cord fibres.

The theory that these degenerations start from hemorrhagic foci is rather losing ground lately, and it seems much more likely they are due to diffuse degeneration affecting certain fibre columns, for in just the cases where hemorrhages occur no such degenerations are usually found.

CASE III.-A male aged forty-eight years; married; born in Bohemia, but came to the United States when ten years old. The cord from this case was kindly given me by Dr. Flexner. 'The patient was admitterl to the Johns Hopkins Hospital in 1901; the autopsy was performed at the hospital. Unfortunately, I can only present a few clinical facts in connection with the case, as I have not obtained the history in full; these notes were taken from the history when the cord was obtained. 'The patient complained of extreme weakness, breathlessness, and vertigo. His occupation has been a coal-miner, and he has been in Pennsylvania about the mines since his boyhood. His previous health has been fairly good. Remembers no serious illness whatever. No pneumonia or typhoid. He has had occasional severe attacks of tonsillitis, which would make him quite ill; he has had about four of these; during one pus was discharged from the tonsil. He has always drunk considerable whiskey. No history of lues or gonorrhoea.

The patient attributes his present illness to stomach trouble, he being fully convinced he has cancer of the stomach, which he believes was caused by a wooden beam striking him across the belly. This was two years before his admission to the hospital. This accident happened after an explosion in the mine, and he, being one of the rescuing party, was exposed to many dangers and to the action of the gases formed by the explosion. He is quite positive that from this day his general health has not been the same. He was very excited at the time and was laid up for about two weeks. The gastric symptoms have been heavy, painful feeling in the epigastrium; occasional attacks of more acute pain. Vomits at times, more in the morning; this has occurred since entering the hospital. No history of jaundice. None of rheumatism. Bowels frequently loose, with intermittent constipation. Notes on physical examination lost.

Description of the Pathological Changes in Case III. 'The same staining methods were employed in the cord from this case as in Case I., the Marchi method not being used. The only change from the normal are several small circumscribed areas of degeneration, 
which are readily seen under the lowest power of the microscope; these were limited to the anterior parts of the cord. On closer examination it is evident that these degenerated fibres were caused by small hemorrhages into the cord substance. Several were found in the upper sacral region, as shown in the illustration, and two wellmarked hemorrhages in the dorsal region between the third and fifth segments. In these the presence of blood pigment is clearly seen, and it easily explains why they should occur in the anterior portion of the cord, this being the most vascular portion. In this case the posterior and lateral columns are absolutely normal. As to the cause of these hemorrhages, they are no doubt due to some changes in the coats of the smaller vessels, very likely a form of hyaline degeneration; 110 doubt the effect of the unknown toxin, which seems to be the etiological factor in this most perplexing dis-

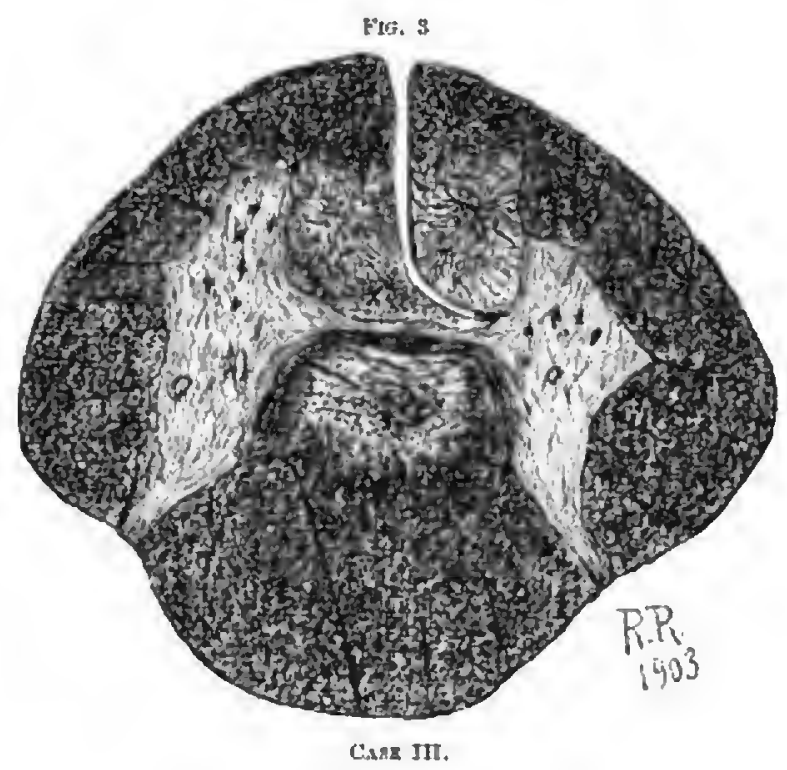

ease. That such degenerations are not found in the ordinary secondary anæmias, even the most severe cases, as those seen after infection with the bothriocephalus, etc., this is well shown in the cases and pathological report of Minnich and Nome on cases of pernicious and secondary anæmias. Lichtheim was the first to call attention to the tabetic-like changes in the spinal cord in pernicious anæmia. In this country the most important article on the spinal changes in this disease is that of Putnam, who also reports several cases in which well-marked spinal symptoms, mostly of a tabetic character, with paræsthetic sensations, preceded the onset of the pernicious anæmia. The reader is also referred to articles of Goldscheider, Nome, Marie, Turner, Minor, and Grasset. 